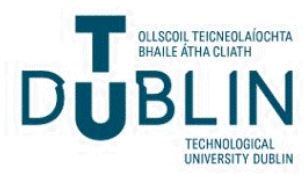

Technological University Dublin

ARROW@TU Dublin

2009-06-18

\section{Radial EBG Cell Layout for GPS Patch Antennas}

\author{
Giuseppe Ruvio \\ Technological University Dublin, Giuseppe.Ruvio@tudublin.ie \\ Max Ammann \\ Technological University Dublin, max.ammann@tudublin.ie \\ Xiulong Bao \\ Technological University Dublin, xiulong.bao@tudublin.ie
}

Follow this and additional works at: https://arrow.tudublin.ie/engscheceart

Part of the Computer Engineering Commons

\section{Recommended Citation}

Ruvio, G., Amman, M. \& Bao, X. (2009) Radial EBG Cell Layout for GPS Patch Antennas. Electronic Letters, Vol. 45, no. 13, June 2009, pp. 663-664 doi:10.1049/el.2009.1145.

This Article is brought to you for free and open access by the School of Electrical and Electronic Engineering at ARROW@TU Dublin. It has been accepted for inclusion in Articles by an authorized administrator of ARROW@TU Dublin. For more information, please contact arrow.admin@tudublin.ie, aisling.coyne@tudublin.ie, gerard.connolly@tudublin.ie.

Funder: Science Foundation Ireland and the Research Support Unit of the Technological University Dublin.

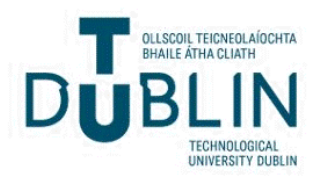




\title{
Radial EBG Cell Layout for GPS Patch Antennas
}

\author{
Giuseppe Ruvio, Max J. Ammann and Xiulong Bao
}

A novel radial layout for mushroom-like electromagnetic-bandgap (EBG) cells surrounding a printed circularly-polarised patch antenna is proposed. Two radial EBG configurations surrounding a circular patch are compared to a reference patch on a conventional ground plane of the same dimension. The radial shape and displacement of the EBG cells around the patch offers improvements in terms of gain and axial-ratio compared to the reference antenna and is more suitable for circular geometries compared to conventional Cartesian layouts. In particular, the distance between the patch and the surrounding EBG cells is independent of the cell period, which can be arbitrarily chosen and the overall layout offers footprint reduction.

Introduction: In recent years numerous designs for EBG cells which surround printed circularly polarised $(\mathrm{CP})$ antennas have been proposed with the aim of improving the axial-ratio (AR) performance. The addition of EBG cells reduce the edge diffraction caused by surface waves which contributes in the far-field to cross-polarised components [1]. Controlling these field components leads to improved AR [2]. The benefits to $\mathrm{CP}$ antenna performance introduced by EBG structures have been particularly notable in positioning systems [3]. Fractal based designs have been proposed to achieve EBG miniaturisation for GPS [4]. In [5] a radial layout of resonating passive printed dipoles was proposed, improving the operating bandwidth and gain of an aperture-coupled printed-dipole antenna. A numerical investigation on different rotationally symmetric EBG configurations surrounding a $15 \mathrm{GHz}$ CP patch antenna was recently reported [6]. Although the gain performance of radial EBG 
antennas is similar to Cartesian layouts, significant design improvement can be achieved with rotationally symmetric EBG arrangements when combined with circular printed patches. Compared to the conventional Cartesian arrangement of EBG cells, a radial layout is more flexible because the distance $d$, between the edge of the patch and the closest row of EBG cells can be freely chosen. This geometric parameter is critical for impedance matching and gain optimisation which in a conventional Cartesian layout is constrained by the EBG cell period and the antenna radius. Thus, the radial layout offers an extra degree of freedom, which is valuable to the antenna designer. The radial layout is also geometrically more suitable for circular patches and circular groundplanes with a resulting reduction of the overall footprint compared to conventional Cartesian layouts.

Configurations investigated: The reference antenna is a circular patch antenna fed by four $50 \Omega$ coaxial probes with a relative phase delay of $90^{\circ}$ to excite RHCP and shorted by a central pin to suppress higher-order modes. The patch radius is $R_{p}=$ $17 \mathrm{~mm}$ and the probes are located $7 \mathrm{~mm}$ from the centre. A Taconic CER10 substrate of dimension $110 \mathrm{~mm} \times 110 \mathrm{~mm} \times 1.58 \mathrm{~mm}$ is used for all antennas. The initial EBG structure used is the well-known mushroom-like Sievenpiper square cell Cartesian array [7]. In order to achieve a bandgap across the GPS $L 1$ band, the period $p=w+I$ of the structure was chosen to be $20.4 \mathrm{~mm}$ (where $w=3 \mathrm{~mm}$ is the separation between adjacent cells and $I=17.4 \mathrm{~mm}$ is the square dimension), so that the overall area of the cell surface is $A=302.76 \mathrm{~mm}^{2}$. The diameter of the grounding vias is $1.3 \mathrm{~mm}$. The dispersion diagram for this structure (Figure 1) shows the bandgap to be from $1.41 \mathrm{GHz}$ to $1.75 \mathrm{GHz}$. This Cartesian array was reshaped into adjacent truncated wedge-shaped sectors to match the rotationally symmetric layout of the circular patch antenna. The area of $302.76 \mathrm{~mm}^{2}$ was maintained which 
is independent of the radius of the patch antenna and the order of the ring to which the cell belongs, and the spacing between cells was $w=3 \mathrm{~mm}$. Two different configurations of EBG cell layouts were evaluated and compared to the reference antenna. They are an 8-sector dual-ring and a 16-sector single-ring radial arrangement as shown in Figure 2. A $1.3 \mathrm{~mm}$ diameter grounding via was centred in each radial cell. Table 1 lists the geometric parameters.

Results: All antennas were well matched (> 10dB RL) in the GPS $L 1$ band and the radiation properties were measured. The measured boresight gain for the reference patch was 3.9 dBic. Although a minor gain enhancement was found for the dual-ring configuration compared to the reference, the single-ring 16-sector cell arrangement presented a gain improvement of $0.6 \mathrm{~dB}$. However, an improvement in boresight AR is realised for both radial EBG configurations. The measured values are $0.75 \mathrm{~dB}$, $0.45 \mathrm{~dB}$ and $0.25 \mathrm{~dB}$ for the reference, dual and single-ring $E B G$ antennas respectively, as shown in Figure 3. The improved gain of the single-ring configuration is due to a greater number of sectors in the ring (16) which offers better resolution in the radial geometry and the resultant bandgap performance, compared to the 8sector layout. The EBG augmented antennas also provide a significantly wider $3 \mathrm{~dB}$ AR beamwidth. The measured AR beamwidths for the reference antenna was $132^{\circ}$, whereas with radial EBG cells this improved to $162^{\circ}$ for single ring to $150^{\circ}$ for the dual ring. The AR beamwidth is particularly important for GPS antennas because improved reception from a larger number of satellites can accelerate the correlation calculation. If the receiver antenna can sufficiently discriminate against indirect counter-polarized signals at lower elevation angles, then the increased visibility of the sky can allow faster correlation of the satellite orbital paths. Finally, figure 4 shows the measured RHCP and LHCP radiation patterns at $1.575 \mathrm{GHz}$ for the three 
prototypes. It can be seen that the artificial surfaces significantly attenuate back radiation due to the suppression of surface waves. The counter polarisation discrimination is also improved. The measured boresight $A R$, gain and counter polarisation rejection is summarised in Table 1.

Conclusion: In this paper two radial layouts of EBG mushroom-like cells have been introduced and compared to a reference CP circular patch antenna. The EBG cells have been shaped in order to match the rotational symmetry of the circular layout. This arrangement allows more design flexibility compared to conventional Cartesian layouts because the distance between the patch antenna and the first ring of EBG cells is independent of the cell period, offering an extra degree of freedom. It also provides a smaller footprint for circular designs. The radial configurations provide improved axial-ratio performance over a larger beamwidth and better cross polarisation characteristics across the hemisphere.

\section{ACKNOWLEDGMENT}

This work was supported by Science Foundation Ireland and the Research Support Unit of the Dublin Institute of Technology. 


\section{References}

[1] F. Yang and Y. Rahmat-Samii, Microstrip Antennas Integrated with Electromagnetic Band-Gap (EBG) Structures: A Low Mutual Coupling Design for Array Applications, IEEE Trans. Antennas Propag., 2003, 51, (10), 29362946.

[2] M. Rahman and M.A. Stuchly, Circularly Polarised Patch Antenna with Periodic Structure, IEE Proc. Microw. Antennas and Propag, 2002, 49, (3), 141-146.

[3] R. Baggen, M. Martinez-Vazquez, J. Leiss, S. Holzwarth, L.S. Drioli and P. de Maagt, Low Profile GALILEO Antenna Using EBG Technology, IEEE Trans Antennas Propag. 2008, 56, (3), 667 - 674.

[4] X.L. Bao, G. Ruvio, M.J. Ammann and M. John, A Novel GPS Patch Antenna on a Fractal Hi-Impedance Surface Substrate, IEEE Antennas Wirel. Propag. Lett., 2006, 5, 323-326.

[5] N. Llombart, A. Neto, G. Gerini and P. de Maagt, Planar Circularly Symmetric EBG Structures for Reducing Surface Waves in Printed Antennas, IEEE Trans. Antennas Propag, 2005, 53 (10), 3210-3218.

[6] G. Ruvio and M.J. Ammann, EBG Mushroom-Like Structures for Enhancing Axial-Ratio Performance of CP Antennas, 1st International Congress on Advanced Electromagnetic Materials for Microwaves and Optics, Rome, Italy, 2007, 727-730.

[7] D. Sievenpiper, L. Zhang, R. Broas, N. Alexopolous and E. Yablonovitch, HighImpedance Electromagnetic Surfaces with a Forbidden Frequency Band, IEEE Trans Microw. Theory Tech. 1999, 47, (11), 2059-2074. 


\section{Figure captions:}

Fig 1. Dispersion diagram

Fig 2. Configurations investigated: (a) two rows of radial EBG cells in 8 sectors; (b) one row of radial EBG cells in 16 sectors

Fig 3. Measured axial-ratio beamwidth at $1.575 \mathrm{GHz}$ for the three prototypes

Fig 4. Measured RHCP and LHCP radiation pattern comparison at $1.575 \mathrm{GHz}$

Table 1. Summary of geometrical parameters and measured performance for the different configurations investigated.

\section{Authors' affiliation:}

Giuseppe Ruvio, Max J. Ammann and Xiulong Bao (Centre for Telecommunications Value-Chain Research, CTVR, School of Electronic and Communications Engineering, Dublin Institute of Technology, Ireland)

\section{Corresponding author:}

giuseppe.ruvio@dit.ie 
Figure 1

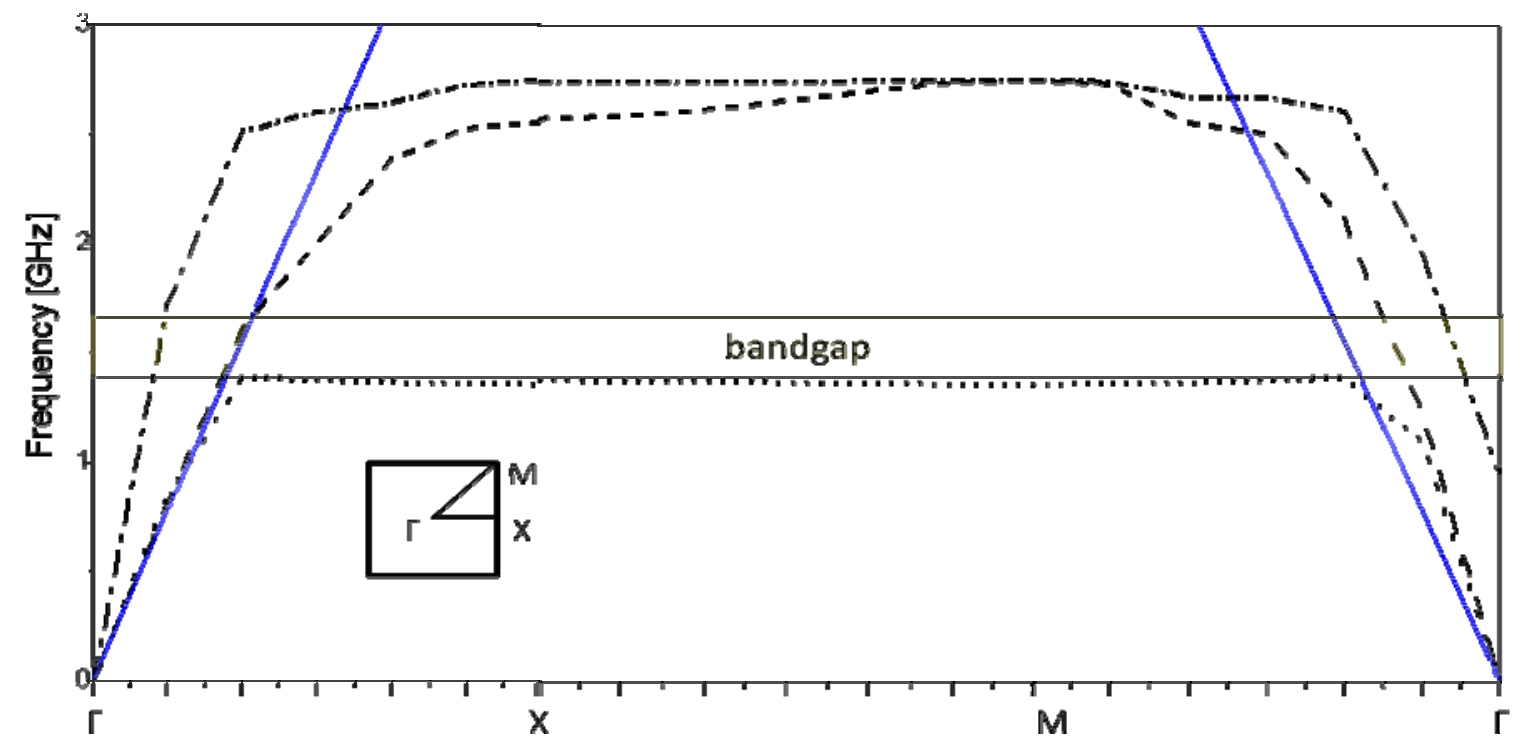


Figure 2

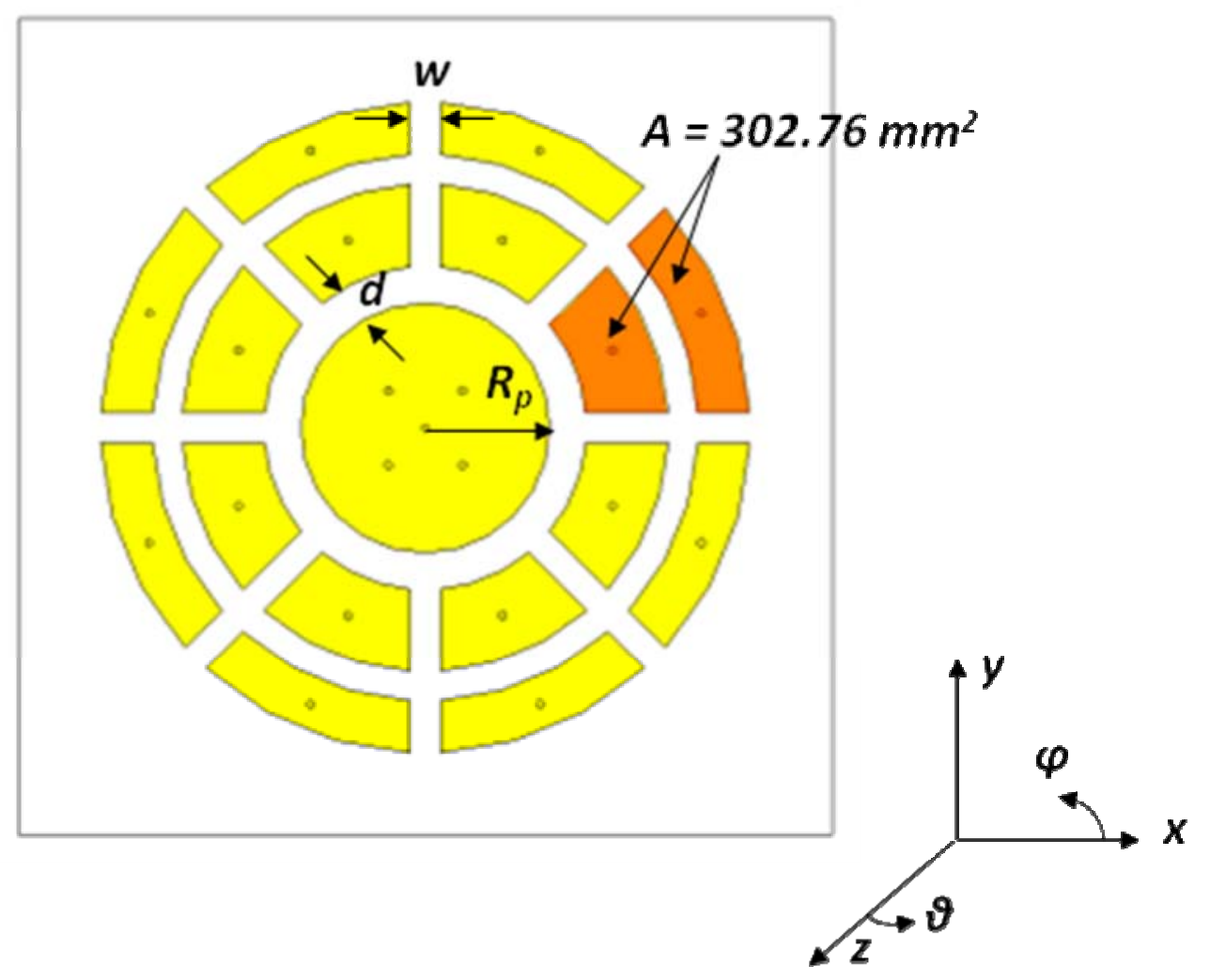

(a)

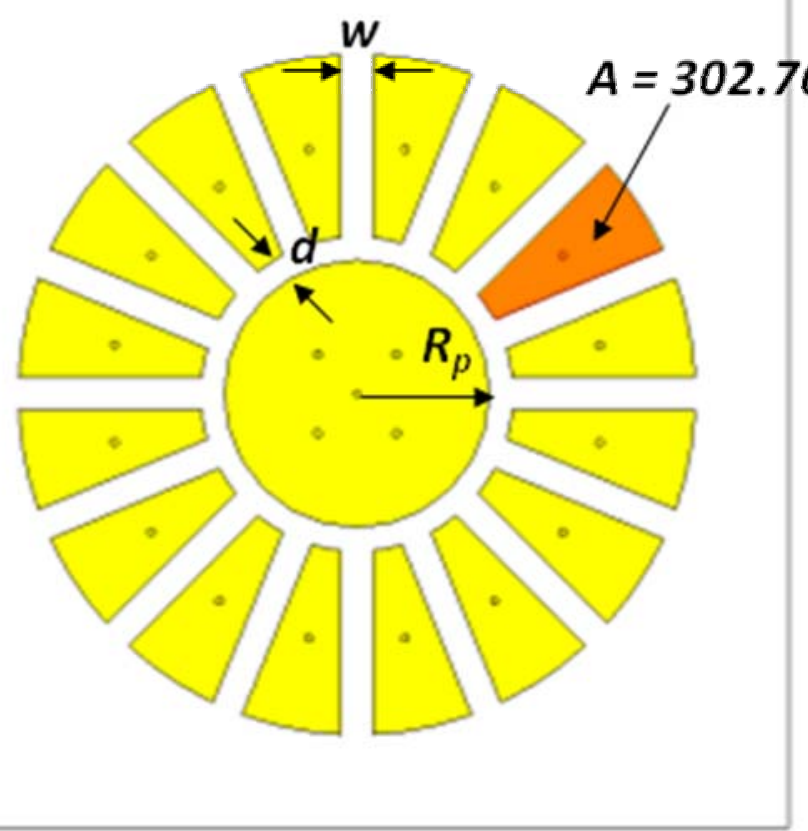

(b) 
Figure 3

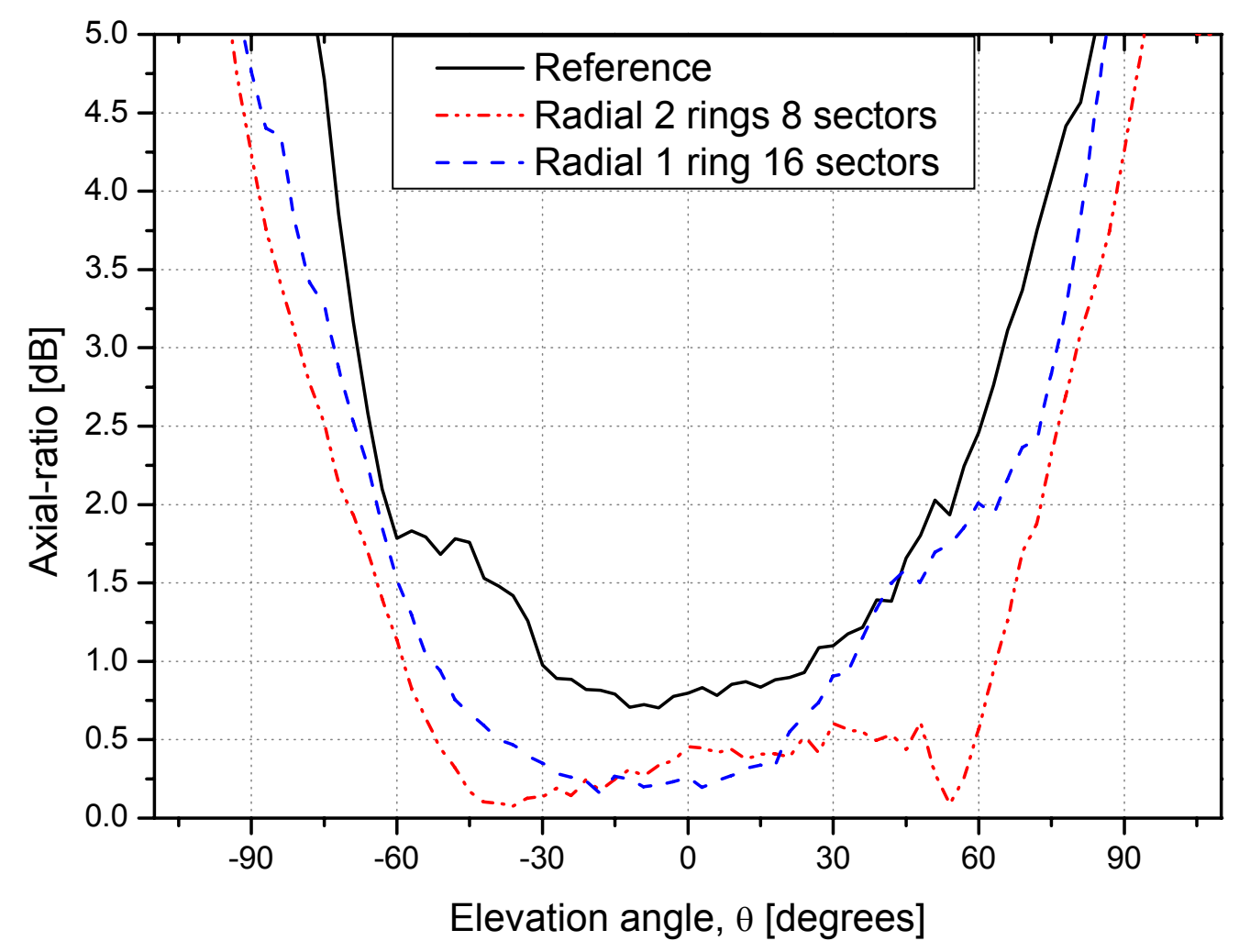


Figure 4

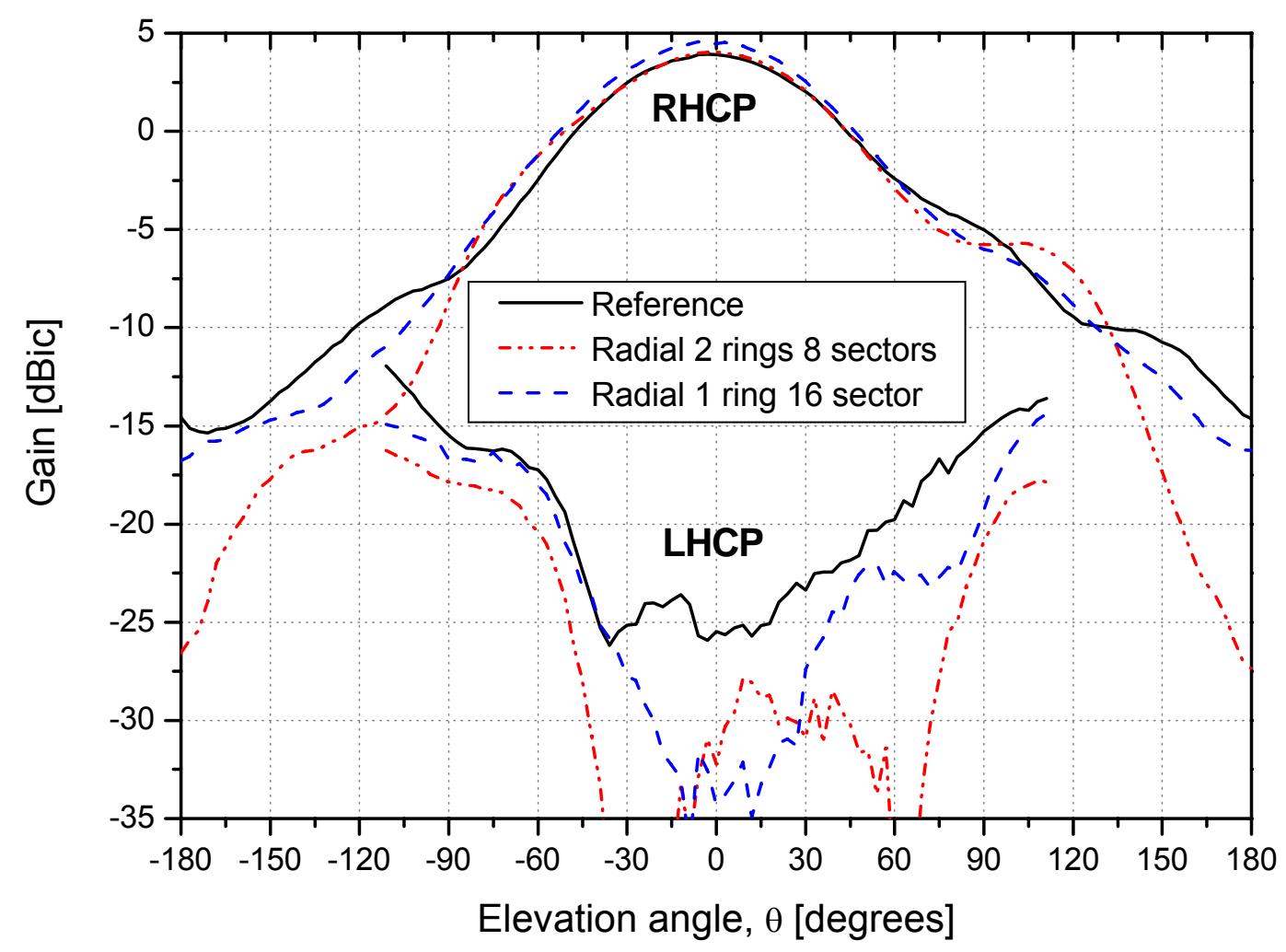


Table 1.

\begin{tabular}{|c|c|c|c|c|c|c|}
\hline Configuration & $\begin{array}{c}R_{p} \\
{[\mathrm{~mm}]}\end{array}$ & $\begin{array}{c}d \\
{[\mathrm{~mm}]}\end{array}$ & $\begin{array}{c}\mathrm{AR} \\
(\mathrm{dB})\end{array}$ & $\begin{array}{c}3 \mathrm{~dB} \text { AR } \\
\text { beamwidth } \\
\left({ }^{\circ}\right)\end{array}$ & $\begin{array}{c}\text { Peak } \\
\text { gain } \\
(\mathrm{dBic})\end{array}$ & $\begin{array}{c}\text { Xpol- } \\
\text { rejection } \\
(\mathrm{dB})\end{array}$ \\
\hline Reference & 17.4 & - & 0.75 & 132 & 3.9 & 30 \\
\hline $\begin{array}{c}2 \text { rings of 8 sector } \\
\text { radial cells }\end{array}$ & 17.3 & 5 & 0.45 & 162 & 4.0 & 36 \\
\hline $\begin{array}{c}1 \text { ring of 16 sector } \\
\text { radial cells }\end{array}$ & 17.4 & 3 & 0.25 & 150 & 4.5 & 39 \\
\hline
\end{tabular}

